\title{
Clinical and quality of life outcomes after aortic valve replacement and aortic root surgery in adult patients $<65$ years old
}

\author{
Arjen L. Gökalp ${ }^{1 \#}$, Frederiek de Heer ${ }^{2 \#}$, Jonathan R. G. Etnel ${ }^{1}$, Jolanda Kluin ${ }^{2}$, Johanna J. M. Takkenberg ${ }^{1}$ \\ ${ }^{1}$ Department of Cardiothoracic Surgery, Erasmus University Medical Center, Rotterdam, The Netherlands; ${ }^{2}$ Amsterdam University Medical Center, \\ Amsterdam, The Netherlands \\ \#These authors contributed equally to this work. \\ Correspondence to: Johanna J. M. Takkenberg, MD, PhD. Professor of Clinical Decision Making in Cardio-Thoracic Interventions, Department of \\ Cardio-Thoracic Surgery, Rg-633, Erasmus University Medical Center, P.O. Box 2040, 3000 CA Rotterdam, The Netherlands. \\ Email: j.j.m.takkenberg@erasmusmc.nl.
}

\begin{abstract}
Selecting the optimal surgical treatment strategy in patients below the age of 65 years (i.e., non-elderly patients) with aortic valve or aortic root disease remains challenging. The objective of the current study is to summarize contemporary research on clinical and quality of life outcomes after aortic valve replacement (AVR) and aortic root surgery in non-elderly patients. Recent systematic reviews on clinical outcome after biological and mechanical AVR, the Ross procedure and aortic root surgery show that event occurrence is considerable after any type of AVR or aortic root surgery and-with the exception of the Ross proceduresurvival is suboptimal. Although thromboembolism and bleeding events are more common after mechanical AVR and root surgery, these events are also considerably present after biological AVR, the Ross procedure and valve-sparing aortic root surgery (VSRR). Similarly, reoperation is more common after biological AVR, the Ross procedure and VSRR, but also occurs frequently after mechanical AVR and root replacement. Published evidence in AVR patients points to the direction of better health-related quality of life (HRQoL) outcomes with a biological solutions, while the HRQoL after aortic root surgery is limited and contradictory. This review illustrates that treatment for non-elderly aortic valve and aortic root disease patients needs to be tailored to the individual patient, considering both clinical and HRQoL outcomes as crucial factors to reach a treatment decision that best reflects the patient's values and goals in life.
\end{abstract}

Keywords: Aortic valve replacement (AVR); aortic root surgery; clinical outcome; quality of life; perspective

Submitted Feb 21, 2019. Accepted for publication Apr 24, 2019.

doi: 10.21037 /acs.2019.04.07

View this article at: http://dx.doi.org/10.21037/acs.2019.04.07

\section{Introduction}

Due to continued improvements in surgical technique and perioperative management, morbidity and mortality after aortic valve and aortic root surgery has decreased $(1,2)$. The available tools in the tool-box of the cardiac surgeon have expanded. Besides the more common surgical procedures (i.e., valve replacement with mechanical or tissue valve prosthesis, with or without replacement of the aortic root), techniques that may be considered include the Ross procedure (3), valve-sparing root replacement and external aortic support [Personalized External Aortic Root Support (4), Florida sleeve (5)]. Under-usage of the more demanding Ross procedure is likely (6). However, not all procedures are equally applicable and careful patient selection is required. The choice for the optimal treatment strategy in patients aged $18-65$ years (i.e., non-elderly patients) with aortic valve or aortic root disease is especially challenging. It requires careful weighing of the risks associated with the various treatment modalities, life expectancy and preferences of these young, mostly active patients. The objective of the current study is to present an overview of clinical outcomes and quality of life after aortic valve replacement (AVR) and aortic root surgery in non-elderly patients. 


\section{AVR}

To provide an overview of contemporary clinical outcomes after AVR, three recently published systematic reviews with meta-analysis and microsimulation analysis will be discussed.

\section{Mechanical aortic valve replacement (MAVR)}

"Mechanical Aortic Valve Replacement in Non-Elderly Adults: Meta-Analysis and Microsimulation" by Korteland et al. (7) is a systematic review and meta-analysis published in 2017 including studies published between 01/1995$12 / 2015$ reporting clinical outcome after contemporary MAVR in patients with a mean age $\geq 18$ and $\leq 55$ years. Twenty-nine papers were included, encompassing 5,728 patients, 32,515 patient-years, and a pooled mean follow-up of 5.7 years. A bileaflet mechanical valve was implanted in $99.9 \%$ of pooled patients.

\section{Bioprosthetic aortic valve replacement (BAVR)}

"Bioprosthetic Aortic Valve Replacement in Nonelderly Adults: A Systematic Review, Meta-Analysis and Microsimulation" by Etnel et al. (8) is a systematic review and meta-analysis published in 2019 including studies published between 01/2001-09/2016 reporting clinical outcome after contemporary BAVR in patients with a mean age between $\geq 18$ and $\leq 55$ years. Nineteen papers were included, encompassing 2,686 patients, 21,117 patientyears, and a pooled mean follow-up of 7.9 years. Fifty-two percent of pooled patients received a porcine biological valve, $47.9 \%$ received a bovine pericardial valve. Seventyeight point two percent of implanted valves were stented, $21.7 \%$ were stentless.

\section{The Ross procedure (Ross)}

"The Ross Procedure: A Systematic Review, Meta-Analysis, and Microsimulation" by Etnel et al. (9) is a systematic review and meta-analysis published in 2018 including studies published between 01/2001-11/2017 reporting clinical outcome after the Ross procedure in adult and/or pediatric patients. Only the adult subgroup was considered in this review, including 35 papers, 6,892 patients, 49,435 patient-years and a pooled mean follow-up of 8.4 years. Ninety-five point three percent of pooled patients received a total root replacement (TRR), 3.8\% received an inclusion cylinder and $0.8 \%$ received a subcoronary implantation.
The right ventricle outflow tract conduit was an allograft in $86 \%$ and a bioprosthesis in $14 \%$.

All three papers used a microsimulation model to extrapolate pooled outcome estimates from the metaanalyses. Details of the concept of microsimulation have been previously published (9-11). In brief, meta-analysisbased estimates of operative and long-term mortality and surgery-related event rates are entered into the microsimulation model.

Using this data, the model estimates age-specific lifetime event risks, life expectancy, event free life expectancy and causes of mortality.

\section{Clinical outcome}

Table 1 depicts the patient and procedural characteristics of the AVR studies. The clinical outcome estimates are depicted in Table 2.

\section{Early morbidity and mortality}

Early stroke rate in MAVR was comparable to early thromboembolism rate in BAVR. Other early events could not be presented due to inconsistent reporting in the included studies. Early mortality risks were comparable after MAVR and BAVR. Early mortality was slightly lower after Ross compared to MAVR and BAVR. This difference is possibly due to the Ross procedure being performed by specialized surgeons (12). Furthermore, a selection bias in Ross patients towards a lower pre-operative risk could be present due to high-risk patients not being selected for the Ross procedure.

\section{Late morbidity}

The valve-related reintervention rate was highest after BAVR and slightly lower after the Ross procedure. Valverelated reintervention rate after MAVR was significantly lower compared to BAVR and Ross, however, still considerable. The reinterventions after MAVR were mostly caused by non-structural valve dysfunction (NSVD), valve thrombosis or prosthetic valve endocarditis. As expected, structural valve deterioration (SVD) was absent in the MAVR population. In the BAVR population, SVD event rate was $1.59 \% / y(95 \%$ CI, $1.21-2.10 \% / y)$. NSVD was comparable between MAVR and BAVR. SVD and NSVD rates could not be presented for the Ross population due to insufficient reporting. 


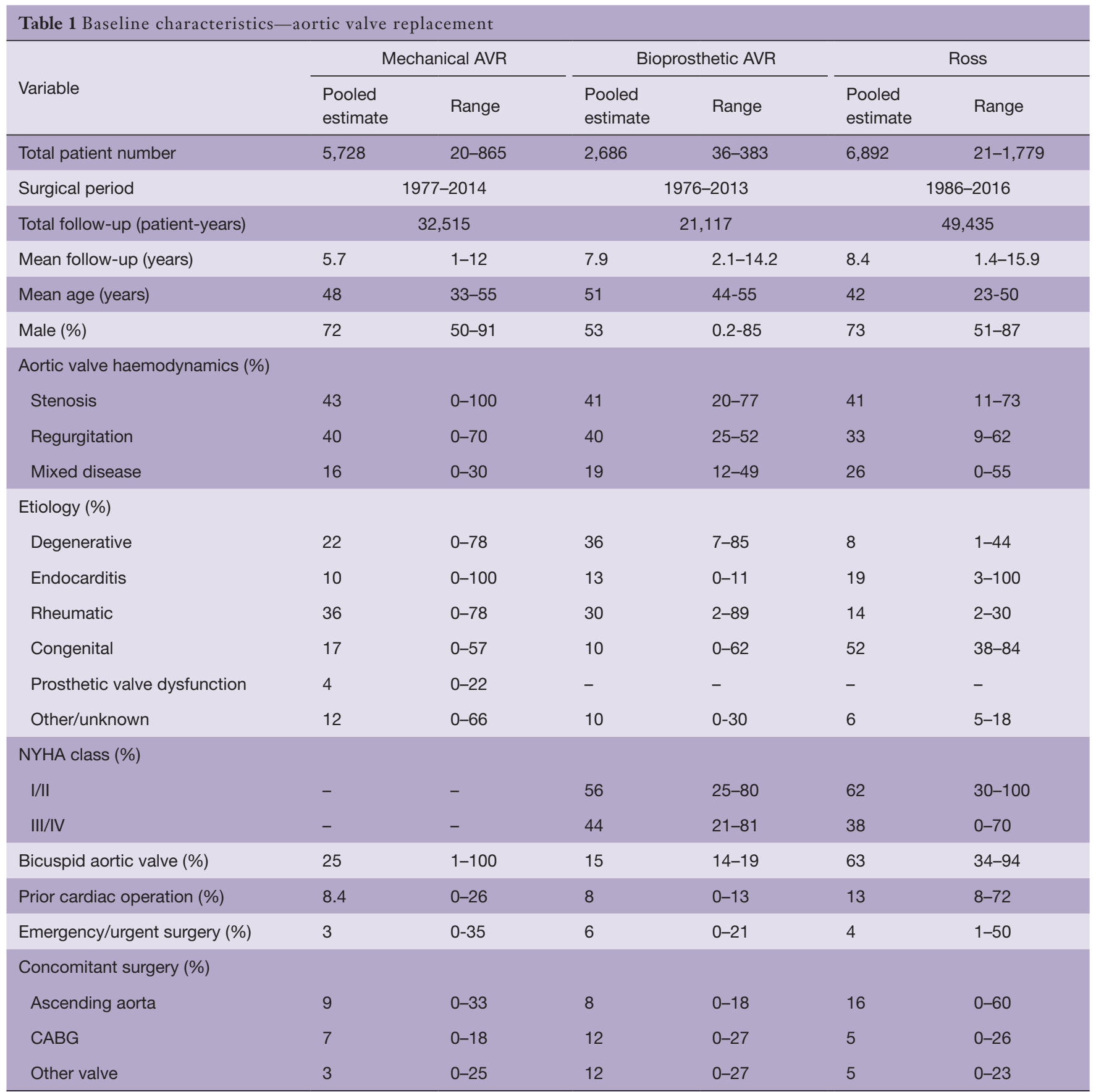

AVR, aortic valve replacement; Ross, the Ross procedure; Range, range of the means of included studies; NYHA, New York Heart Association; CABG, coronary artery bypass grafting.

Thromboembolism rates were significantly higher after MAVR compared to BAVR and Ross. Major bleeding event rates were higher in MAVR compared to BAVR and Ross, due to the use of oral anticoagulant therapy after MAVR. Although lower compared to MAVR, anticoagulant therapy related events were considerable in BAVR and Ross and should be taken into consideration in prosthetic valve selection. Event risks accumulate during the patients' lifetime and are considerable, especially in young patients. This accumulation of risks ("lifetime event risks") can be calculated 
Table 2 Outcome estimates-aortic valve replacement

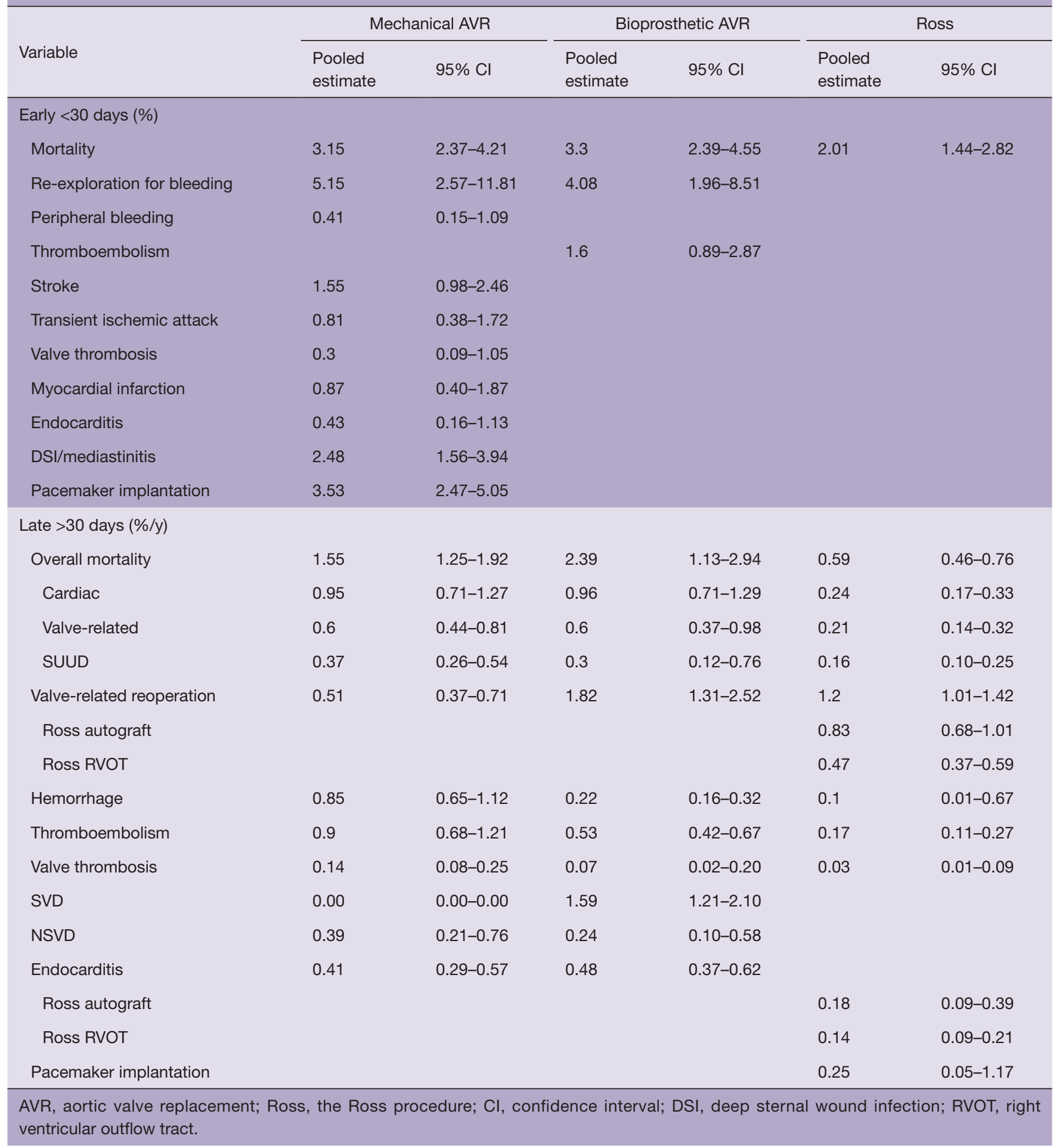




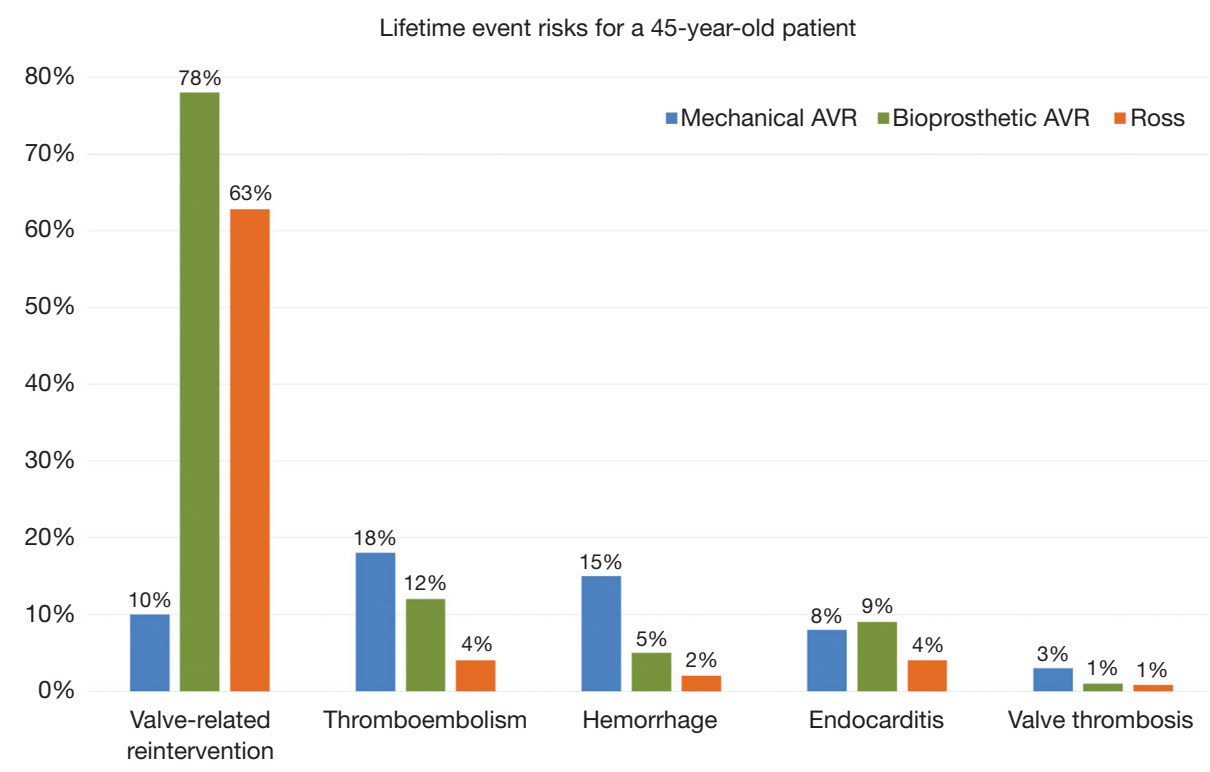

Figure 1 Microsimulation estimated lifetime event risks for a 45-year-old mechanical AVR, biological AVR or Ross patient. For Ross valverelated reintervention both autograft and RVOT reinterventions are included: isolated autograft reintervention $43.46 \%$, isolated RVOT reintervention $14.09 \%$, concomitant autograft + RVOT reintervention 5.23\%. AVR, aortic valve replacement; RVOT, right ventricular outflow tract.

using microsimulation. The lifetime event risks for a 45 -yearold patient receiving either a MAVR, BAVR or a Ross procedure are presented in Figure 1. It is important to note that these estimates should not be compared between the populations due to the differences in patient characteristics. Visualization of lifetime risks using microsimulation provides more comprehensive insight into the risks for an individual patient and can aid in decision-making.

\section{Late mortality}

Late overall mortality rates were highest after BAVR, followed by MAVR. Late overall mortality after the Ross procedure was significantly lower compared to mechanical and bioprosthetic AVR. Late valve-related mortality rates were comparable between mechanical and bioprosthetic AVR and significantly lower after the Ross procedure. Whether the observed difference is due to patient selection or due to the Ross procedure providing the patient with a living neo-aortic valve with excellent hemodynamics, is a topic of debate.

The higher overall mortality in BAVR patients might be due to a worse preoperative profile, including older age, larger proportion of female patients and degenerative etiology. BAVR patients also undergo concomitant CABG and valve procedures more often, suggesting more advanced cardiac disease. In addition, BAVR patients might have a lower life expectancy due to various reasons and therefore receive a BAVR, causing a selection bias.

The higher overall mortality in BAVR patients is not likely to be attributable to the differences in valve-related mortality causes, as is shown by the comparable late valverelated mortality. This is important when considering prosthetic valve selection.

Ross patients have lower postoperative endocarditis, thromboembolism and bleeding rates, possibly explaining the lower late mortality rate. The difference in overall and valve-related mortality in Ross patients is small, suggesting that there is little excess mortality. This might be due to their preoperative profile (i.e., younger patients, lower NYHA class, congenital etiology), specialized surgeons and excellent hemodynamics following the Ross procedure $(12,13)$. In addition, patients receiving the Ross procedure might experience better postoperative surveillance due to the complexity of the surgery and the specialization of institutions in which they are operated. Another factor that might contribute is that congenital patients and patients with a higher socio-economic status or education level might be more involved in their disease and treatment decision-making, do more research, and therefore choose 


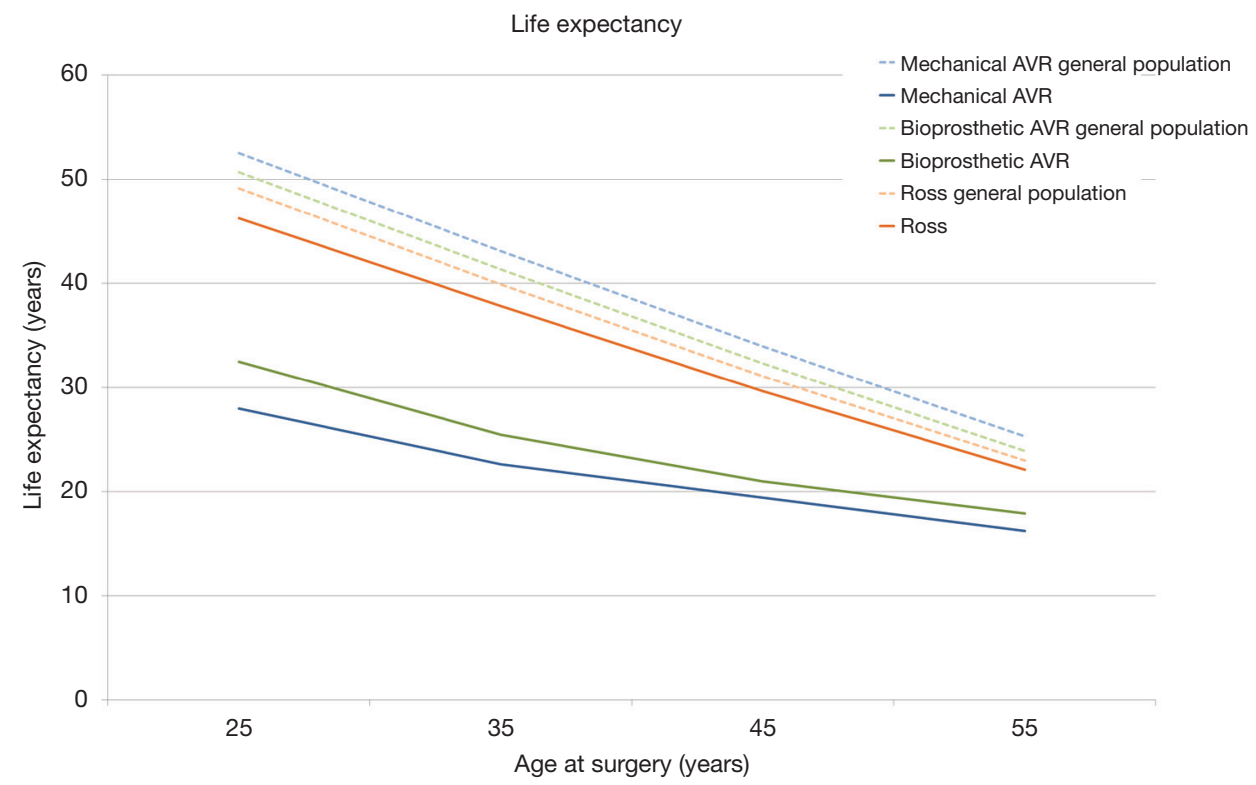

Figure 2 Microsimulation estimated life expectancy following mechanical AVR, biological AVR and Ross surgery (solid lines) and age- and sex-matched general population (dashed lines). AVR, aortic valve replacement.

the Ross procedure more often. This type of patient might also be more involved in their postoperative care and thus receive better care and in addition might generally live a healthier lifestyle $(14,15)$. This underlines the need for more patient involvement and empowerment to improve clinical outcome and quality of life.

The meta-analysis based microsimulation estimates of life expectancy for patients undergoing MAVR, BAVR and Ross are presented in Figure 2 alongside the respective general population life expectancies. It is important to note that the differences between the interventional population estimates cannot be compared as they were derived from different study populations.

\section{Aortic root surgery}

Two recent systematic reviews with meta-analysis give an overview of current available evidence for outcomes after mechanical TRR and valve-sparing root replacement.

\section{Total root replacement (TRR)}

Mookhoek et al. published a meta-analysis of the reported outcomes after mechanical Bentall operations (16). They included 46 studies and a total of 7,629 patients, operated between 1968-2012. Mean clinical follow-up was 6.4 years (range, 3.0-10.4 years), resulting in 49,175 patient-years. The pooled average age was 49.8 years.

\section{Valve sparing root replacement (VSRR)}

Arabkhani et al. published a meta-analysis of reported outcomes after valve-sparing aortic root replacement in 2015 (17). Their search resulted in 31 reports over a 14-year period [2000-2014], including 4,777 patients, operated between 1988-2012. Mean clinical follow-up was 4.4 years (range, 1.5-13.2 years) and 21,716 patients-years. The pooled average age was 51.0 years.

\section{Clinical outcome}

The pooled pre- and perioperative characteristics of both studies are depicted in Table 3. Table 4 depicts the pooled early and late clinical outcomes.

\section{Early mortality}

Early morbidity was not reported in the systematic reviews. Pooled early mortality was higher after TRR compared to VSRR. This difference can be explained by the higher prevalence of emergency surgery, aortic dissections and previous cardiac surgery in the TRR population. 


\begin{tabular}{|c|c|c|c|c|}
\hline Variable & Pooled estimate & Range & Pooled estimate & Range \\
\hline Total patient number & 7,629 & $40-675$ & 4,777 & $32-430$ \\
\hline Surgical period & \multicolumn{2}{|c|}{ 1968-2012 } & \multicolumn{2}{|c|}{ 1988-2012 } \\
\hline Mean follow-up (years) & 6.4 & $3-10.4$ & 4.4 & $1.5-13.2$ \\
\hline Mean age (years) & 50 & $29-65$ & 51 & $29-63$ \\
\hline Male (\%) & 76 & $55-91$ & 71 & $57-85$ \\
\hline \multicolumn{5}{|l|}{ Aortic valve haemodynamics (\%) } \\
\hline \multicolumn{5}{|l|}{ Mixed disease } \\
\hline Type A dissection (\%) & 15 & $0-39$ & 11 & $0-33$ \\
\hline Endocarditis (\%) & 2 & $0-15$ & & \\
\hline Connective tissue disease (\%) & 23 & $0-100$ & 24 & $0-100$ \\
\hline Bicuspid aortic valve (\%) & 25 & $4-100$ & 14 & $0-33$ \\
\hline Prior cardiac operation (\%) & 16 & $1-7$ & 4 & $2-12$ \\
\hline Mechanical valve (\%) & 93 & $43-100$ & & \\
\hline \multicolumn{5}{|l|}{ Concomitant surgery (\%) } \\
\hline
\end{tabular}

\section{Late morbidity}

Reoperation rates were higher after VSRR compared to TRR. Bleeding rates were higher after TRR, due to the mandatory use of life-long anticoagulation therapy in TRR.

\section{Late mortality}

The pooled late mortality rate was lower after VSRR compared to TRR. This difference can be explained by the preoperative differences between the populations and the lower overall event occurrence in the VSRR population. However, it should be stressed that a direct comparison between these two populations cannot be made using these data.

\section{Health related quality of life outcomes}

There is a growing body of observational evidence on quality of life after AVR. The landmark paper by Aicher et al. studied quality of life and anxiety and depression after mechanical valve implantation, the Ross procedure and aortic valve repair. It found that quality of life, including valve-related aspects such as valve sound, frequency of doctor visits and fear of potential complications, is influenced by the type of operation. Patients who received mechanical prostheses had worse general health, physical functioning and mental health and more cardiac-related anxiety (18). These observations have been confirmed by several other studies, that all point into the direction of a better QoL with a biological solution $(19,20)$. 


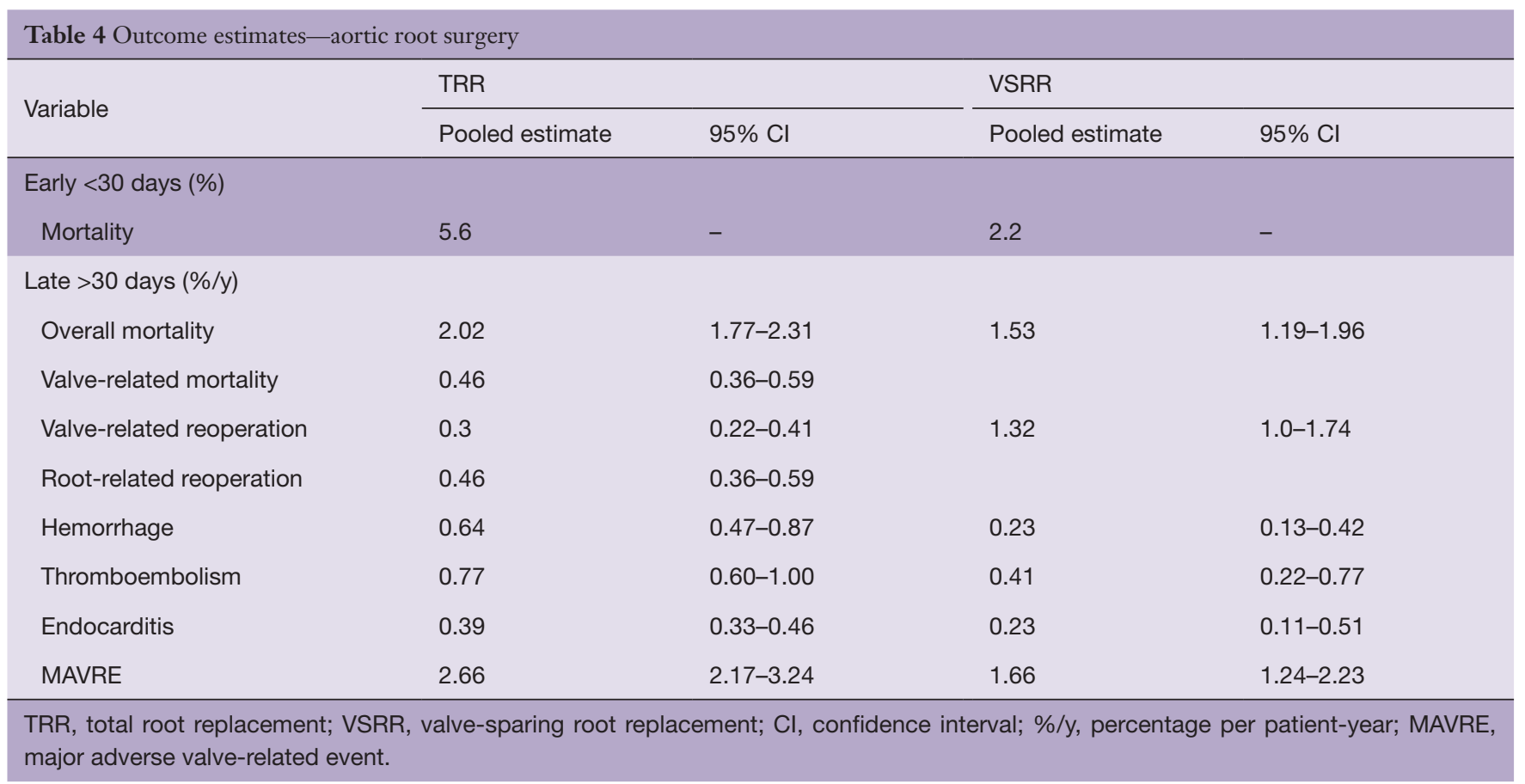

Contemporary evidence on QoL outcomes after aortic root surgery was reviewed by de Heer et al. and showed that limited and only observational data with contradicting results are available (21). Although a study by Olsson et al. in 1999 showed significantly worse health-related QoL outcomes for patients after thoracic aortic surgery compared to the general population, an updated study in 2013 showed comparable QoL $(22,23)$. This may be the result of advances in cardiac surgery and improved cardiovascular care in more recent years and is in agreement with other recent studies that report QoL in thoracic aortic surgery patients to be comparable to the general population (24-26). There is some evidence on differences in QoL between aortic root surgery strategies: observational evidence suggests that QoL after surgery is significantly worse in most of the domains of the SF-36 in patients after TRR versus VSRR surgery. TRR patients reported to be significantly more disturbed by valve sound, more afraid that their valve will fail and assigned a lower score to their overall condition (27). There is no evidence that there is a difference between mechanical versus biological TRR surgery (28).

Given these observations, the notion arises that it is important to consider QoL as a crucial factor in treatment selection for both AVR and aortic root surgery, in order to reach an evidence-based and patient-centered treatment decision that best reflects the patient's values and goals in life. The concept of shared decision-making allows physicians and patients to reach such decisions, and is gaining interest throughout the world and even in the European and US guidelines for the management of valvular heart disease $(29,30)$. There is growing evidence that tools to support shared decision-making in prosthetic heart valve selection are indeed effective in reducing anxiety and depression and improving mental health and knowledge in patients who are facing heart valve replacement (31).

\section{Future perspectives}

\section{Patient tailored treatment}

The continued decline in mortality after aortic valve and aortic root surgery over the years calls for a shift in focus in clinical decision-making towards quality of life. As demonstrated by the evidence outlined above, all currently available options for aortic valve and root surgery remain imperfect. The outcome profiles of the various treatment options are in stark contrast to one another, each with different implications for many aspects of patients' lives, both physical and psychosocial.

As treatment decisions have such an important impact on patients' lives, choosing the optimal treatment tailored for each patient with regard for individual values, preferences and 
life planning is of utmost importance. Because preferences and treatment goals vary between individual patients and also between patients and their physicians, involvement of patients in the decision-making process is essential. Although both physicians and patients have been found to prefer shared roles in decision-making, physicians still experience substantial difficulty in adequately informing and involving their patients (32-34). Thus, there is an urgent need for innovative solutions to aid in more effectively informing and involving patients. In this light, online patient information portals and decision aids present promising opportunities $(31,35)$. Methods for elucidating patients' values, preferences and treatment goals and how these can effectively be incorporated in decision-making should be explored.

The evolution of clinical outcome over the years should also translate to a shift in research focus from classical outcome measures such as survival and event occurrence towards patient-centered outcomes that better reflect what is valuable and meaningful to patients. It remains to be elucidated which outcomes patients value most after aortic valve and aortic root surgery. In any case, high quality evidence on clinical outcome remains indispensable. The AVIATOR initiative of the Heart Valve Society (HVS) is a longitudinal multicenter international registry that focuses on patients with aortic valve insufficiency and/or a dilated ascending aorta. The wish is to embrace the complete disease trajectory, starting from the diagnoses, including operation and long-time follow-up. Since 2013 the AVIATOR Adult Surgical Registry is enrolling patients and comprises already 5,000 cases (36). Furthermore, the HVS started a new initiative to evaluate prosthetic AVR: the LEOPARD registry. These multicenter registries should provide a solid evidence base, by applying uniform definitions, to evaluate long-term patient outcomes for the different treatment strategies for aortic valve root disease in non-elderly patients. The addition of quality of life outcomes to the AVIATOR and LEOPARD registries could be of great added value.

\section{Novel treatment strategies}

Unfortunately, "one valve for life" is not yet on the horizon. Research into tissue engineered valves has made great progress, however in vivo use in humans is not yet available $(37,38)$. Meanwhile, other novel treatment strategies are available that are possibly underutilized.

Advances in aortic valve repair might provide improved outcomes. Furthermore, minimally invasive techniques are developing. In the prevention of further aortic root dilatation in Marfan patients, a new stabilization technique was introduced: Personalized External Aortic Root Support (PEARS). The individual's aortic root is replicated by a 3-dimensional printed model to produce an individualized polymer mesh sleeve, which is wrapped around the aorta. Over a 12-year period [2004-2016] more than 60 patients were treated with PEARS in six centers (4).

With the promise of more durable bioprostheses, the possibility of transcatheter valve-in-valve procedures might become available for younger patients. However, both the prolonged durability of bioprostheses and transcatheter valve-in-valve outcomes are not sufficiently researched in non-elderly patients.

If anticoagulation therapy is unavoidable, reducing associated events is of great importance. New mechanical prostheses are being developed that require lower INR levels (39). Optimized anticoagulation therapy through selfmanagement can achieve comparable survival between Ross patients and MAVR patients (40). Two studies included in the BAVR systematic review reported that at the end of follow-up $25-30 \%$ of the BAVR patients required oral anticoagulants, mostly due to atrial fibrillation $(41,42)$. In an effort to reduce anticoagulation-related events, characteristics that put BAVR patients at risk for atrial fibrillation should be explored. Furthermore, research into the use of NOAC's for atrial fibrillation shows this might be a safe treatment strategy in BAVR (43).

\section{Conclusions}

This review provides an overview of current evidence on aortic valve and aortic root replacement in non-elderly adults. The differences in clinical outcome between treatment options are not a black-and-white issue and this underlines the need for individual patient tailored treatment and shared decision-making. Involved and empowered patients can make informed decisions and consequently experience improved clinical outcome and quality of life.

\section{Acknowledgments}

Funding: This work was supported by The Netherlands Organisation for Health Research and Development (grant number 849200014).

\section{Footnote}

Conflicts of Interest: The authors have no conflicts of interest 
to declare.

\section{References}

1. Siregar S, de Heer F, Groenwold RH, et al. Trends and outcomes of valve surgery: 16-year results of Netherlands Cardiac Surgery National Database. Eur J Cardiothorac Surg 2014;46:386-97; discussion 397.

2. Fujita B, Ensminger S, Bauer T, et al. Trends in practice and outcomes from 2011 to 2015 for surgical aortic valve replacement: an update from the German Aortic Valve Registry on 42776 patients. Eur J Cardiothorac Surg 2018;53:552-9.

3. Ross DN. Replacement of aortic and mitral valves with a pulmonary autograft. Lancet 1967;2:956-8.

4. Treasure T, Petrou M, Rosendahl U, et al. Personalized external aortic root support: a review of the current status. Eur J Cardiothorac Surg 2016;50:400-4.

5. Hess PJ Jr, Klodell CT, Beaver TM, et al. The Florida sleeve: a new technique for aortic root remodeling with preservation of the aortic valve and sinuses. Ann Thorac Surg 2005;80:748-50.

6. Yacoub MH, El-Hamamsy I, Sievers HH, et al. Underuse of the Ross operation--a lost opportunity. Lancet 2014;384:559-60.

7. Korteland NM, Etnel JR, Arabkhani B, et al. Mechanical aortic valve replacement in non-elderly adults: metaanalysis and microsimulation. Eur Heart J 2017;38:3370-7.

8. Etnel JRG, Huygens SA, Grashuis P, et al. Bioprosthetic Aortic Valve Replacement in Nonelderly Adults: A Systematic Review, Meta-Analysis, Microsimulation. Circ Cardiovasc Qual Outcomes 2019;12:e005481.

9. Etnel JR, Grashuis P, Huygens SA, et al. The Ross Procedure: A Systematic Review, Meta-Analysis, and Microsimulation. Circ Cardiovasc Qual Outcomes 2018;11:e004748.

10. Puvimanasinghe JP, Takkenberg JJ, Edwards MB, et al. Comparison of outcomes after aortic valve replacement with a mechanical valve or a bioprosthesis using microsimulation. Heart 2004;90:1172-8.

11. Huygens SA, Rutten-van Molken MP, Bekkers JA, et al. Conceptual model for early health technology assessment of current and novel heart valve interventions. Open Heart 2016;3:e000500.

12. Ouzounian M, Mazine A, David TE. The Ross procedure is the best operation to treat aortic stenosis in young and middle-aged adults. J Thorac Cardiovasc Surg 2017;154:778-82.
13. Um KJ, McClure GR, Belley-Cote EP, et al. Hemodynamic outcomes of the Ross procedure versus other aortic valve replacement: a systematic review and meta-analysis. J Cardiovasc Surg (Torino) 2018;59:462-70.

14. Mosen DM, Schmittdiel J, Hibbard J, et al. Is patient activation associated with outcomes of care for adults with chronic conditions? J Ambul Care Manage 2007;30:21-9.

15. Goossens E, Fieuws S, Van Deyk K, et al. Effectiveness of structured education on knowledge and health behaviors in patients with congenital heart disease. J Pediatr 2015;166:1370-6.e1.

16. Mookhoek A, Korteland NM, Arabkhani B, et al. Bentall Procedure: A Systematic Review and Meta-Analysis. Ann Thorac Surg 2016;101:1684-9.

17. Arabkhani B, Mookhoek A, Di Centa I, et al. Reported Outcome After Valve-Sparing Aortic Root Replacement for Aortic Root Aneurysm: A Systematic Review and Meta-Analysis. Ann Thorac Surg 2015;100:1126-31.

18. Aicher D, Holz A, Feldner S, et al. Quality of life after aortic valve surgery: replacement versus reconstruction. J Thorac Cardiovasc Surg 2011;142:e19-24.

19. Ruel M, Kulik A, Lam BK, et al. Long-term outcomes of valve replacement with modern prostheses in young adults. Eur J Cardiothorac Surg 2005;27:425-33; discussion 433.

20. Zacek P, Holubec T, Vobornik M, et al. Quality of life after aortic valve repair is similar to Ross patients and superior to mechanical valve replacement: a cross-sectional study. BMC Cardiovasc Disord 2016;16:63.

21. de Heer F, Gokalp AL, Kluin J, et al. Measuring what matters to the patient: health related quality of life after aortic valve and thoracic aortic surgery. Gen Thorac Cardiovasc Surg 2019;67:37-43.

22. Olsson C, Thelin S, Stahle E, et al. Thoracic aortic aneurysm and dissection: increasing prevalence and improved outcomes reported in a nationwide populationbased study of more than 14,000 cases from 1987 to 2002 . Circulation 2006;114:2611-8.

23. Olsson C, Thelin S. Quality of life in survivors of thoracic aortic surgery. Ann Thorac Surg 1999;67:1262-7.

24. Jarral OA, Kidher E, Patel VM, et al. Quality of life after intervention on the thoracic aorta. Eur J Cardiothorac Surg 2016;49:369-89.

25. Lohse F, Lang N, Schiller W, et al. Quality of life after replacement of the ascending aorta in patients with true aneurysms. Tex Heart Inst J 2009;36:104-10.

26. Stalder M, Staffelbach S, Immer FF, et al. Aortic root replacement does not affect outcome and quality of life. Ann Thorac Surg 2007;84:775-80; discussion 780-1. 
27. Franke UF, Isecke A, Nagib R, et al. Quality of life after aortic root surgery: reimplantation technique versus composite replacement. Ann Thorac Surg 2010;90:1869-75.

28. Lehr EJ, Wang PZ, Oreopoulos A, et al. Midterm outcomes and quality of life of aortic root replacement: mechanical vs biological conduits. Can J Cardiol 2011;27:262.e15-20.

29. Baumgartner H, Falk V, Bax JJ, et al. 2017 ESC/EACTS Guidelines for the management of valvular heart disease. Eur Heart J 2017;38:2739-91.

30. Nishimura RA, Otto CM, Bonow RO, et al. 2014 AHA/ ACC guideline for the management of patients with valvular heart disease: a report of the American College of Cardiology/American Heart Association Task Force on Practice Guidelines. J Thorac Cardiovasc Surg 2014;148:e1-132.

31. Korteland NM, Ahmed Y, Koolbergen DR, et al. Does the Use of a Decision Aid Improve Decision Making in Prosthetic Heart Valve Selection? A Multicenter Randomized Trial. Circ Cardiovasc Qual Outcomes 2017. doi: 10.1161/CIRCOUTCOMES.116.003178.

32. Etnel JRG, Helbing WA, Roos-Hesselink JW, et al. Patient and physician view on patient information and decision-making in congenital aortic and pulmonary valve surgery. Open Heart 2018;5:e000872.

33. Korteland NM, Kluin J, Klautz RJ, et al. Cardiologist and cardiac surgeon view on decision-making in prosthetic aortic valve selection: does profession matter? Neth Heart J 2014;22:336-43.

34. Korteland NM, Bras FJ, van Hout FM, et al. Prosthetic aortic valve selection: current patient experience, preferences and knowledge. Open Heart 2015;2:e000237.

35. Etnel JR, van Dijk AP, Kluin J, et al. Development of an Online, Evidence-Based Patient Information Portal for Congenital Heart Disease: A Pilot Study. Front Cardiovasc
Med 2017;4:25.

36. de Heer F, Kluin J, Elkhoury G, et al. AVIATOR: An open international registry to evaluate medical and surgical outcomes of aortic valve insufficiency and ascending aorta aneurysm. J Thorac Cardiovasc Surg 2018. [Epub ahead of print].

37. Hjortnaes J, Bouten CV, Van Herwerden LA, et al. Translating autologous heart valve tissue engineering from bench to bed. Tissue Eng Part B Rev 2009;15:307-17.

38. Nachlas AL, Li S, Davis ME. Developing a Clinically Relevant Tissue Engineered Heart Valve-A Review of Current Approaches. Adv Healthc Mater 2017. doi: 10.1002/adhm.201700918.

39. Torella M, Aquila I, Chiodini P, et al. Low-dose anticoagulation after isolated mechanical aortic valve replacement with Liva Nova Bicarbon prosthesis: A post hoc analysis of LOWERING-IT Trial. Sci Rep 2018;8:8405.

40. Mokhles MM, Kortke H, Stierle U, et al. Survival comparison of the Ross procedure and mechanical valve replacement with optimal self-management anticoagulation therapy: propensity-matched cohort study. Circulation 2011;123:31-8.

41. Forcillo J, El Hamamsy I, Stevens LM, et al. The perimount valve in the aortic position: twenty-year experience with patients under 60 years old. Ann Thorac Surg 2014;97:1526-32.

42. Minakata K, Tanaka S, Takahara Y, et al. Long-term durability of pericardial valves in the aortic position in younger patients: when does reoperation become necessary? J Card Surg 2015;30:405-13.

43. Andrade JG, Meseguer E, Didier R, et al. Non-vitamin K antagonist oral anticoagulants in atrial fibrillation patients with bioprosthetic valves. Expert Rev Cardiovasc Ther 2018. [Epub ahead of print]
Cite this article as: Gökalp AL, de Heer F, Etnel JR, Kluin J, Takkenberg JJ. Clinical and quality of life outcomes after aortic valve replacement and aortic root surgery in adult patients $<65$ years old. Ann Cardiothorac Surg 2019;8(3):372-382. doi: 10.21037/acs.2019.04.07 